\title{
HOW TO INTERPRET ENTRIES
}

\section{EXAMPLE 1: ENGLISH-NUKUORO}

SAMPle Entries

EXPLANATIONS

breechclout

Breechclout: huna;malohuna;

malo sabo ${ }^{\circ}$

${ }^{1}$ Archaic words are marked with asterisks.

Bruguiera $^{2}$

Plant sp.: oriental mangrove (Bruguiera gymnorhiza (L.) Lam. $)^{3}$ : donga.

${ }^{2}$ Plant and animal genera (but not species) names are invariably listed.

${ }^{3}$ Binomials are listed only for plant and animal species which have been identified by taxonomists.

butterfly

Butterfly: bebe ${ }_{2}{ }^{4}$

butterfly fish

Fish sp.: butterfly fish ${ }^{5}$ :

dihidihi.
${ }^{4}$ Numerical subscripts

distinguish homonyms.

${ }^{5}$ English species names not accompanied by binomial identification indicate that positive identification was possible only to a generic or higher degree, owing to the lack of a suitable specimen. 
SAMPLE ENTRIES

\section{buttocks}

Buttocks: dae $_{3}{ }^{6}$

Having flat buttocks, ugly (because not plump):

biihingi.

\section{Explanations}

${ }^{6}$ Note that not all meanings of each Nukuoro word are given in the English-Nukuoro section. $\mathrm{Dae}_{3}$, for example, also means 'guts, intestines'. The additional meanings of a word, also information on word class and derivation are found in the Nukuoro-English section. 


\section{EXAMPLE 2: NUKUORO-ENGLISH}

SAMPLE ENTRIES

$a-3^{1}$.

PLURAL PREFIX. ${ }^{2} m f$.

aapulu. (E--3 ABULU)

Sink all at once. ${ }^{4} a^{5}$.

aapuluanga. (E-1 ABULU)

$$
n .^{6}
$$

aada. $^{7}$

Easily startled, skittish, wild (of animals). $a$.
EXPLANATIONS

${ }^{1}$ Numerical subscripts distinguish homonyms. (The hyphen indicates that this is a prefix.)

${ }^{2}$ Grammatical designations and grammatical information appear in small capitals.

${ }^{3}$ Derivation information (between parentheses): this consists of a "derivative-type code" and the root (see page 487 , under which related forms may be found in the Root List.

${ }^{4}$ Gloss.

5 "Word-class code" (see page xxiii).

${ }^{6}$ There is no gloss for this word because normal derivatives are not glossed (see Appendix 1).

${ }^{7}$ Bases (always single words, by definition) have no derivation information if the base form is identical to the form of the root. For related forms consult the Root List under the form of the base. 
Nukuoro Lexicon .

SAMPle ENTries

aadea moana $^{8}$

Unobstructed.
ExPLANations

${ }^{8}$ Idioms (always two or more words, by definition) have no derivation information. For related forms consult the Root List under the root form of each constituent word.

aduhale. $\left(\mathrm{ADU}_{4}{ }^{9}, \mathrm{HALE}\right)$ Village, compound (aggregation of houses); go from house to house. $a$.
${ }^{9}$ Compound words list their constituent roots and no derivative-type code. amuamu (R-- AMU)

$-;{ }^{10}$ small and useless particles, leftovers. $v$.

ana $_{2}$

[var. of kana]. ${ }^{11} \mathrm{mt}$.
${ }^{10} \mathrm{~A}$ dash in the gloss section indicates that this form has the meanings of a normal derivative (see note 6 above) in addition to those listed. (See also note 5 in example 3 below).

${ }^{11}$ Comment by the compilers is enclosed in brackets. The listing of variants is arbitrary in that either one could be listed as a variant of the other. 


\section{EXAMPLE 3: ROOT LIST}

SAMPle EnTries

ADU $_{+}{ }^{1}$

$\mathrm{B}^{2} \quad \operatorname{adu}_{4} \cdot n^{3}$. Conglomerate, islet.

$\mathrm{XCO}$ adudau. n. Sand spit.
EXPLANATIONS

${ }^{1}$ Roots which are spelled the same but have different patterns of affixation are numbered apart.

${ }^{2}$ Derivative-type code.

${ }^{3}$ Word-class code.

${ }^{4}$ Compounds which have many derivatives are given a letter subscript for convenience in organizing the associated entries. The choice of root under which such forms are listed is arbitrary.

${ }^{5}$ Normal derivatives are not glossed (see Appendix 1).

BE 1 hagaadugauanga. n. -

BE 2 hagaadugaua. $v$. -

BE 2 hagaadugaulia. $v$. -

ID adugau daane. Part of the plug of the pandanus. 